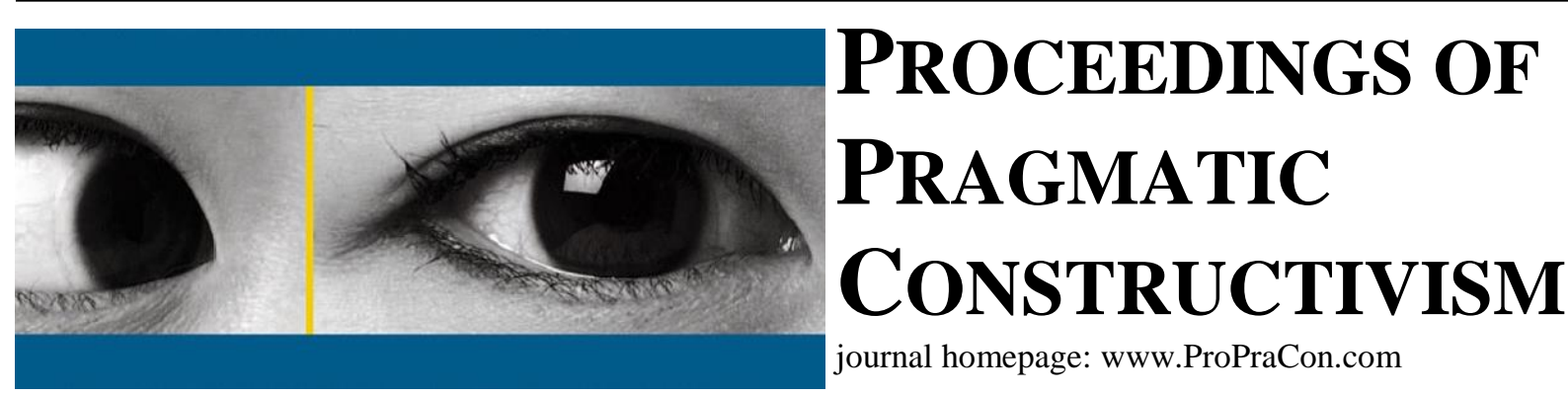

\title{
Digitalization and validity in business planning. The case of a global retailer
}

\author{
Antonio Leotta \\ University of Catania, UNICT · Department of Economics and Business \\ E-mail: antonio.leotta@unict.it \\ Lino Cinquini \\ Scuola Superiore Sant'Anna of Pisa, Institute of Management \\ E-mail: l.cinquini@santannapisa.it \\ Carmela Rizza \\ University of Catania, UNICT · Department of Economics and Business \\ E-mail: c.rizza@unict.it \\ Daniela Ruggeri \\ University of Catania, UNICT · Department of Economics and Business \\ E-mail: d.ruggeri@unict.it \\ Andrea Tenucci \\ Scuola Superiore Sant'Anna of Pisa, Institute of Management \\ E-mail: a.tenucci@santannapisa.it
}

In the management accounting practice, digitalization seems to have facilitated the development and use of performance measurement systems. The use of digital tools enriches sources of data useful for the construction of performance measures, and allows a company's organizational areas to share performance measures, supporting people communications and collective decisions. These supposed advantages are due to the development of standardized algorithms and formulas that ensure the mobility and the integration of data and information, centralizing the method of their production. The consequence is a clear separation between the producers and the users of data with the risk of using accounting calculations as answer machines and no longer as a basis for judgement. This risk occurs in planning and budgeting processes where participants are willing to increase the accuracy of forecasts, relying on standardized algorithms in simulating the future. A rather different use of digitalized calculations refers to the sharing of data for communications that enable collective discussions and judgments, according to the argument that "budgets are important for the process that they require for their construction, not for the outcomes that they generate” (Quattrone, 2016).

Digitalization is opened to different uses, as the ones mentioned above, and thereby to different meanings of validity of data and figures it produces. As Kalthoff (2005) reported from a case evidence on financial risk management practice: "right figures are legitimized through the methods of their production because these methods are framed by (Western) economics and thus assumed to be reliable and valid" (ibidem, p. 78). 
The aim of the research is to examine how digitalization influences the validity of planning and budgeting procedures. In doing so, we rely on the concept of validity based on pragmatic constructivism. The latter considers valid a plan or a budget that comes from a process whose participants have integrated the business facts they have observed with their values and developed future possibilities communicated through accounting language. Where valid, the planning and budgeting process represents a step of a larger process of strategic learning. For this process to be successful, "the conduction of the authoring process should balance contributions from participating actors" (Nørreklit, 2017, p. 28) leading to an orchestrated authorship where organizational individuals are not only actors but also coauthors of the narratives and causalities produced. The validity of processes in this respect produces reality and not illusions: the latter originates not only from a non-functional relation between the individual actor and the world (Nørreklit, 2011, p. 19), but it can also be the result of a failed integration between organizational topoi that incapacitates the ability of the actors to pursue the desired changes, and generates illusion instead.

The theoretical lens outlined above is adopted to interpret the use of a digital tool within the planning process at a multinational retailer operating in the industry of furniture. The choice of the Company is due to the philosophy of management control it follows. Management control follows a holistic approach where the management control manager engages the other managers and himself in defining and pursuing both strategic and operational objectives, translating them from the corporate to the country and the store levels, in monitoring their achievement, and furthermore, in exploring emergent strategic options that can create new business possibilities. The annual planning procedure takes place through a negotiation process where management control managers and store managers interact across corporate, country and store levels. This leads them to articulate the business plan into three main goals: 1 ) mandatory goals, related to business and organizational problems already observed and to be solved; 2) recommended goals, related to potential problems that may occur if something is not put in practice. This is the case of maintenance activities, whose relevance depends on the local characteristics of each store; 3) optional goals, which are identified and proposed at the store level, where specific strategic options can be caught. The latter kind of objectives entails some criticalities as they are identified not from the observation of the business facts but through exploring the local business environment and selecting the opportunities that have potentials to become factual possibilities. Exploring its specific local market and social environment, each store identifies optional objectives and how to pursue them, so defining a specific local strategy of business development. Therefore, a double line of coherence shapes the strategic planning: company coherence, which relates strategic objectives with company's values, and local coherence, where the single store relates strategic goals to local specificities. This leads to the question: how can the business plan be valid given the various objectives defined at different levels? Put it in pragmatic constructivist words: how can the local coherence be matched with company coherence? How different organizational topoi (corporate, country and local level) coexist?

We addressed this question examining the use of a digital corporate tool through which the various stores share the performance of their practices. The levels of the store's performance are comparable being the stores positioned into clusters characterized by homogeneous strategies of local business development. For the stores in the same cluster this tool makes possible a benchmark analysis which allows each store to verify the feasibility of optional objectives and to monitor the achievement.

Data are drawn from two main organizational levels, namely the country and the store levels. The country level refers to the Italian headquarter of the Company, whereas the store level refers to the Sicilian store located in Catania and the Tuscany store located in Pisa.

The case evidence is examined in order to highlight whether the use of such digital tool facilitates the integration of the different organizational topoi, articulated into the corporate, the country and the store levels as well as the integration amongst the topoi of the stores within the same strategic cluster and the topoi of the stores across the clusters. Very importantly, in exploring the use of such tools, the paper tries to point out what kind of integration of topoi and validity of the processes they support, whether through merging or coherence, is achieved by their use.

\section{References}

Kalthoff, H. (2005). Practices of calculation: Economic representations and risk management. Theory, Culture \& Society, 22(2), 69-97.

Nørreklit, L. (2011). Actors and reality: a conceptual framework for creative governance. In M. J. Jakobsen, Inga-Lill and Nørreklit, Hanne (Ed.), An Actor's Approach to Management (pp. 7-38). Copenhagen: DJØF Publishing.

Nørreklit, L. (2017). Actor-reality Construction. In H. Nørreklit (Ed.), A Philosophy of Management Accounting (pp. 23-71): Routledge.

Quattrone, P. (2016). Management accounting goes digital: Will the move make it wiser? Management Accounting Research, 31, 118-122. 